\title{
Fault Diagnosis of Uncertain Systems Based on Interval Fuzzy PETRI Net
}

\section{Fatma LAJMI, Achraf Jabeur TALMOUDI, Hedi DHOUIBI}

LARATSI, National Engineering School of Monastir 5000 Street Ibn El Jazzar - Monastir 5035, , Tunisia

flajmi@yahoo.fr; achraf_telmoudi@yahoo.fr, hedi.dhouibi@laposte.net

\begin{abstract}
The purpose of the following article is a novel approach to modeling, diagnosis and control of discrete event systems. This approach uses the Petri net Fuzzy Interval (IFPN) to describe the diagnosis system. The Petri network is used to model the system which needs to be controlled. This work is a description of a case study applied to an ingredient mixing system where the concentration of ingredients has to be held within a valid range.
\end{abstract}

Keywords: Uncertain systems, Intervals Fuzzy Petri Nets, Modelling, Fault Diagnosis.

\section{Introduction}

Fault diagnosis in dynamic systems has been the subject of several research works. It is defined as a process of detecting any deviation or intended behaviour of a system and isolating the cause of this failure. There are many approach diagnosis and technical processes [1, $5,10,16,17,18,23,24,29]$ that have been applied to fault diagnosis of dynamic systems. Their goals are focused on a timely diagnosis of defects in order to provide a precise judgment rule for distribution operators. Particularly when serious defects occur in a system, a lot of alarm information is transmitted to the control system. In such cases operators must quickly and accurately assess the causes, location and defect system components. Diagnosing faults with the right methods can provide accurate and effective diagnostic information for ship operators and help them take adequate action in certain faulty situations to ensure safety.

In the context of diagnosis more model-based systems have been used: finite state machine [17, 8], Petri nets [9, 31, 34, 35, 38]. Despite the various researches in recent years and the proposed modeling approaches for the fault diagnosis, several unresolved problems have remained.

The performances of the diagnostic approaches depend on the means of the model being used. Obtaining and using the model to construct a diagnosis system is a complex and difficult task more particularly for the uncertain systems because of unforeseen and uncontrollable events that characterize them.

This paper focuses on fault diagnosis of uncertain discrete-event systems and tries to use Interval Fuzzy Constrained Petri Nets (IFCPN) as a tool of modelling, identification and isolation.

The proposed tool IFCPN model is introduced in order to extend some properties of the Interval Constraint Petri Nets $[13,14]$ which is considered as an extension the P-temporal Petri Net [26] and a sub-class of High Level PN $[21,25]$.

Our main contribution is to extend the functional range of ICPN applications to fault diagnosis of uncertain systems where the validity intervals of any parameter are fuzzy and characterized by the propagation of uncertain events $[4,15,30]$.

This paper is organized as follows: In the first part of this work, we studied the modelling of a mixing system: we propose an approach using Statistical Process Control in order to build the validity ranges of fuzzy intervals and we compute robust control laws of this model.

In the second part we study the robustness of a system which is defined as its ability to maintain the concentration properties specified on the occurrence of disruptions. After having proved this robustness we use the tool built for the diagnosis of the defaults. The diagnosis method is based on fuzzy logic [37]. 


\section{Interval Constrained Petri Nets (ICPN)}

ICPN model allows modelling and guaranteeing a constraint on any parameter of dynamic systems.

Definition [14]:

An Interval Constraint $\mathrm{PN}$ is a t-uple:

$$
<R, m, I_{S}, D, V, V_{0}, X, X_{0}>
$$

where:

- $\quad R$ is a marked Petri Net model

- $m$ is the application: $m: P \rightarrow \mu \Theta$ that associates a token to places:

where $\Theta$ is a set of formulas (non-empty) and $\mu \Theta$ is a multiset defined on $V$.

- $I_{S}: P \rightarrow R \cup\{-\infty,+\infty\} \times R \cup\left(Q^{+} \cup\{-\infty,+\infty\}\right)$ defines the static intervals associated to the places of $\mathrm{PN}$.

- D defines an application:

$$
D: m(p) \times P \rightarrow V a
$$

that associates a rational $q \leq b_{i}$ to pair (place, token). It results from a variation of the value of a token which associated in a place.

- $X$ defines an application: $X: V a \rightarrow Q$ that assigns to each variable a value: $v a \rightarrow u \in Q$;

- $X_{0}$ defines the initial values.

- $V$ associates a formula to each token $(K)$ of rational values.

- $V_{0}$ is the initial formulas which is associated to the token.

A token in place $p_{i}$ is taken into account in transition validations if and only if it has reached a value comprised between the limits of the static interval $\left[\mathrm{a}_{\mathrm{i}}, \mathrm{b}_{\mathrm{i}}\right]$.

After the firing of an upstream transition, tokens are generated in output places and their values will be equal to:

$\mathrm{V}(\mathrm{k})+\mathrm{q}$

We did not specify the meaning of parameter $\mathrm{q}$ and $\mathrm{V}(\mathrm{k})$ to generalize the model.

For more details see [14]

\section{Interval Fuzzy Petri Nets}

\subsection{Definition:}

The concept of an Interval Fuzzy Petri Nets (IFPN) $[20,36]$ is derived from the ICPN model where we define IS as a fuzzy interval associated with places [36]. This model is used to represent a fuzzy rule-based system that is capable of modeling the fuzzy production rules (type if $p_{j}$ and $p_{k}$ with certainty Factor $\left.\mu_{\mathrm{i}}\right)[3,7,27]$.

The theory of fuzzy interval has found applications for modeling and controlling uncertain presentation systems [2, 7, 19, 27] in the settings. Knowing that a conventional interval includes all possible values, in a fuzzy range we associate a degree of uncertainty for each of the possible values.

In this article, we introduce a method for calculating the limits of a given range. First we present in the following lines the basic concepts of conventional and fuzzy intervals.

\subsection{Conventional interval}

A number of the fuzzy interval $\boldsymbol{U}$ is defined as the set of real numbers $\mathbf{x}$ such that:

$I_{F}=\left[i^{-}, i^{+}\right]=\left\{x \in R / i^{-} \leq x \leq i^{+}\right\}$

Let's consider two closed intervals of reel numbers:

$I_{F}=\left[i^{-}, i^{+}\right]$and $\mathrm{L}_{F}=\left[l^{-}, l^{+}\right]$

The arithmetic operations in the interval are defined as follows [30, 32]:

- Addition: $I_{F}+L_{F}=\left[i^{-}+l^{-}, i^{+}+l^{+}\right]$

- Subtraction:

$I_{F}-L_{F}=\left[i^{-}-l^{+}, i^{+}-l^{-}\right]$

- Multiplication:

$I_{F} \times L_{F}=\left[\operatorname{Min}\left(I_{F}\right), \operatorname{Max}\left(I_{F}\right)\right]$, where $I=\left[i^{-} i^{-}, i^{-} i^{+}, i^{+} i^{-}, i^{+} i^{+}\right]$

- Division: $\frac{1}{I_{F}}=\left[\frac{1}{i^{+}}, \frac{1}{i^{-}}\right]$if $0 \notin I_{F}$

$-\frac{I_{F}}{L_{F}}=\left[\begin{array}{c}\min \left(\frac{i^{-}}{l^{-}}, \frac{i^{-}}{l^{+}}, \frac{i^{+}}{l^{-}}, \frac{i^{+}}{l^{+}}\right), \\ \max \left(\frac{i^{-}}{l^{-}}, \frac{i^{-}}{l^{+}}, \frac{i^{+}}{l^{-}}, \frac{i^{+}}{l^{+}}\right)\end{array}\right]$ 


\subsection{Fuzzy interval}

A fuzzy interval $I_{F}$ is defined as a conventional interval to which is associated a membership function denoted $\mu_{I}$ :

$$
\mu_{i}=\left\{\begin{array}{l}
R \rightarrow[0,1] \\
x \rightarrow \mu_{i}(x)
\end{array}\right.
$$

In a fuzzy interval each value has a degree of belonging. The higher it is the more plausible the value.

If the membership function is a trapezoidal or triangular function, this interval can be expressed by the following relations:

- Case 1: trapezoidal function:

$$
I_{F}=\left[i^{-}, i^{+}\right]: \operatorname{Core}\left(I_{F}\right)=\left[\left(i^{\bmod }\right)^{-},\left(i^{\bmod }\right)^{+}\right]
$$

- Case 2: triangular function:

$$
I_{F}=\left[i^{-}, i^{+}\right]: \text {Core }\left(I_{F}\right)=\left[I_{F}^{\bmod }\right]
$$

The Core represents the plausible values.

Fuzzy concepts [36] are based on more membership functions (trapezoidal, triangular, Gaussian ...) and the rules if ...then.

The trapezoidal and triangular membership functions are most frequently used. These two functions make it possible to transform the numerical values into fuzzy spaces.

In this work, we use the triangular function defined by $\mathrm{l}_{\mathrm{m}}$ and $\mathrm{I}_{\mathrm{h}}$, respectively, the lower and the upper limit.

We also use the trapezoidal function with variable intervals depending on the slopes which vary between $0 \%$ and $100 \%$ (high function value).

In this analysis the probabilities are included in the representation of the numbers, so that the fuzzy intervals may be first described with a base and then with a larger interval. Figure 1 shows the three fuzzy intervals A, B and C of the level $\mathrm{h}$ with different bases and tops.

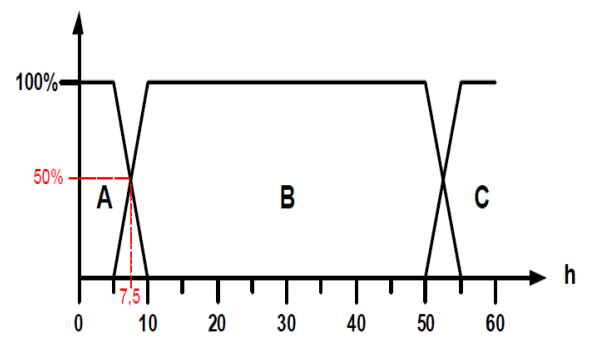

Figure 1: Example of Fuzzy intervals

$$
\begin{aligned}
& \mathrm{h} 1=[(0,10):(0,5)] \\
& \mathrm{h} 2=[(5,55):(10,50)] \\
& \mathrm{h} 3=[(50,60):(55,60)]
\end{aligned}
$$

Moreover, in the fuzzy theory, the rules must be expressed in terms of fuzzy variables and is to be placed in fuzzy space.

In this work we combine two methods: we use mathematical equations to construct the limits of intervals and secondly we use the rules to determine the faults. To do this, one must define the qualitative arithmetic which allows mathematical operations on qualitative numbers. The basic operations required are addition and subtraction.

Consider the operations of addition and subtraction of two fuzzy intervals h1 and h2 of figure. 2 . They are performed as the operations on the conventional intervals.

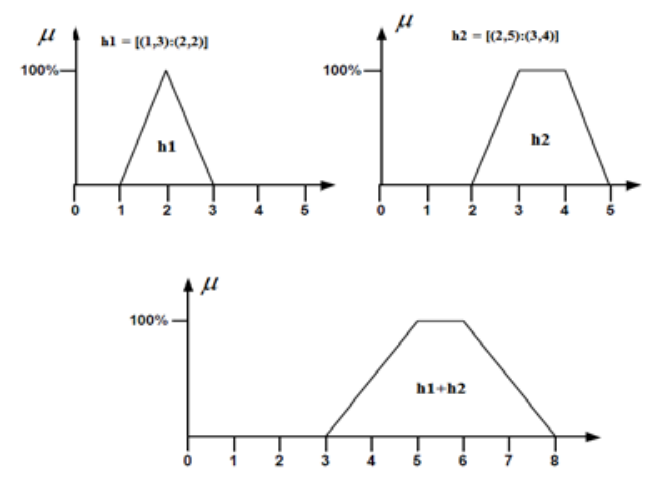

Figure 2: Fuzzy interval operations addition

\section{Fuzzy IF - THEN Rules}

The concept of fuzzy IF-THEN $[15,36]$ is frequently used for describing logical dependence between variables of the following form:

\section{IF $V_{1}$ is $K_{1} A N D V_{n}$ is $K_{n}$ THEN $U$ is $M$.}

We define with $\mathrm{K}_{1}, \ldots, \mathrm{K}_{\mathrm{n}}$ and $\mathrm{M}$ as the predicates which characterizes the variables $\mathrm{V}_{1}$, $\ldots, \mathrm{V}_{\mathrm{n}}$ and $\mathrm{U}$. These variables have often specified as typically linguistically. Our work is based on these specific linguistic expressions. The variables $\mathrm{V}_{1}, \ldots, \mathrm{V}_{\mathrm{n}}$ are often called independent inputs or variables. $\mathrm{M}$ is the output variable (dependent variable). 
Example of the linguistic description:

Rule1 $=I F V_{1}$ is $X_{11}$ AND ...AND $V_{n}$ is $X_{1 n}$ THEN $U$ is $M_{1} \ldots$

Rule $m=I F V_{1}$ is $X_{m 1}$ AND ...AND $V_{n}$ is $X_{m n}$ THEN $U$ is $M_{m}$

The relation between fuzzy PN and the linguistic description "IF THEN rules" is obvious. Figure 3 shows this correspondence between fuzzy PN and "IF THEN" rule of the above previous form:

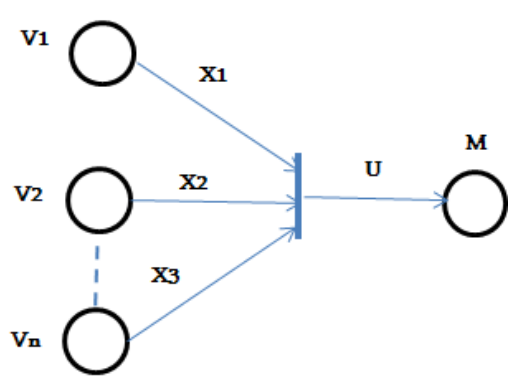

Figure 3. Correspondence between linguistic description and one rule "IF-THEN".

\section{Workshop modeling}

Modelling with IFPN will be illustrated on example of mixing system (Figure 4). We simplify it as much as possible to show described modeling technique. Two ingredients Q1 and Q2 are filled in the mixer tank and then mixed with water. The quantity of each ingredient as well as that of the water is adjusted by a modulating valve. The total quantity must not exceed $95 \%$ of the total capacity of the tank. After the mixing operation the product will be filled in bottles to be marketed. The quality of the product depends on the concentration limits of mixture's ingredients that we want to keep constant.

There are 5 steps in the mixing process:

step1: Add Ingredient Q1

step2: Add Ingredient Q2

step3: Add Water

step4: Mix the products

step5: Product filling

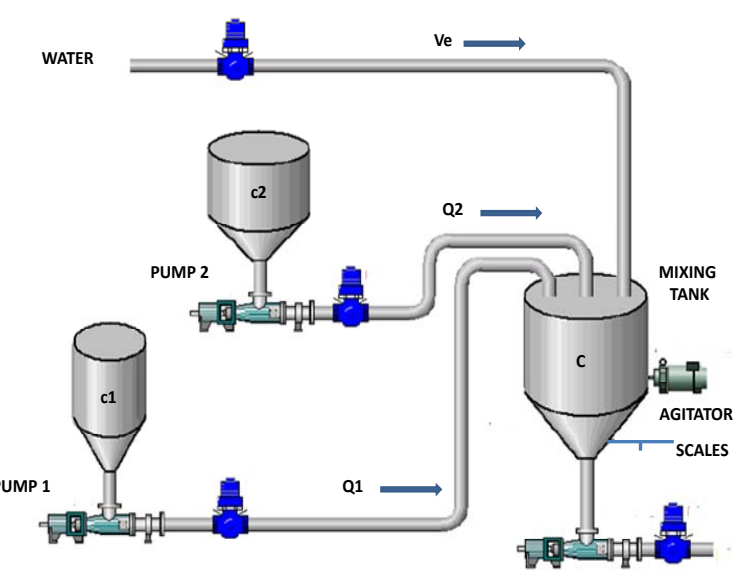

Figure 4. Mixing system

Considering the following relationship:

$$
C=\frac{m_{1}+m_{2}}{V e}
$$

Where:

$\mathrm{m}_{1}$ is the masse of product $1 \mathrm{in} \mathrm{kg}$

$\mathrm{m}_{2}$ is the masse of product $2 \mathrm{in} \mathrm{kg}$

Ve: volume of water in $\mathrm{mm}^{3}$

Such that:

$m_{1}=C_{1} V_{1}$ and $m_{2}=C_{2} V_{2}$ where $\mathrm{Ci}$ an $\mathrm{V}_{\mathrm{i}}$ are respectively the concentration (in $\mathrm{Kg} / \mathrm{mm}^{3}$ ) and the volume (in $\mathrm{mm}^{3}$ ) of the product Qi $(\mathrm{i}=1,2)$.

The relation (2) can be written as following:

$$
C=\frac{C_{1} h_{1} S+C_{2} h_{2} S}{V e}
$$

C is the concentration of the final product in $\mathrm{Kg} / \mathrm{mm}^{3}$. There is a validity range of this parameter:

$\mathrm{C} \in\left[\mathbf{C}_{\min }, \mathbf{C}_{\max }\right]$.

An out of range value of the concentration $\mathbf{C}$, the product will be rejected.

The variation of $\mathrm{C}$ depends on those of $\mathrm{C} 1$ and $\mathrm{C} 2$. Our aim is to control the specifications required for concentration $\mathrm{C}$ and to maintain these values within a validity interval:

$\mathbf{C}_{1}$ is the concentration of the final product in $\mathrm{Kg} / \mathrm{mm}^{3}$. And there is a validity range of this parameter:

$\mathrm{C}_{1} \in\left[\mathbf{C}_{1 \min }, \mathbf{C}_{1 \max }\right]$.

$\mathbf{C}_{2}$ is the concentration of final product in $\mathrm{K} / \mathrm{mm}^{3}$. There is a validity range of this parameter:

$\mathrm{C}_{2} \in\left[\mathbf{C}_{2 \min }, \mathbf{C}_{2 \max }\right]$. 
Ve is the volume of water in $\mathrm{mm}^{3}$ : with:

$\mathrm{Ve} \in\left[\mathbf{V} \mathbf{e}_{\text {min }}, \mathbf{V e}_{\mathbf{m a x}}\right]$

S: is a section of tank in $\mathrm{mm}^{2}$

$$
C_{\min } \leq \frac{C_{1} h_{1} S+C_{2} h_{2} S}{V e} \leq C_{\max }
$$

\subsection{Possibility of simulation:}

The construction of the model requires a prior calculation of the tolerances on each parameter. For this purpose it is possible to use the simulation on real values from statistical data on production $[11,22,28]$. The following paragraph describes the steps of this method of calculation and the assumptions taken into consideration

\subsection{Linearization approximation}

We suppose that the variation of the parameters around the mean is very small. Then we can approximate the relationship (eq. 3) by the first order linearization in the neighborhoods of the reference setting:

$\Delta \mathrm{C} \in\left[\Delta \mathrm{C}_{\min }, \Delta \mathrm{C}_{\max }\right]$

Either $\mathrm{C}_{0}, \mathrm{C}_{10}, \mathrm{~h}_{10}, \mathrm{C}_{20}, \mathrm{~V}_{20}$ and $\mathrm{V}_{\mathrm{e} 0}$, are respectively the values targets of parameters $C$, $\mathrm{C}_{1}, \mathrm{~h}_{1}, \mathrm{C}_{2}, \mathrm{~h}_{2}$ and $\mathrm{V}_{\mathrm{e}}$. After linearization of equation (3) around the operating point we can write:

$$
\begin{aligned}
& C \approx C_{0}+\frac{\delta C}{\delta c_{1}}\left(c_{1}-C_{10}\right)+\frac{\delta C}{\delta h_{1}}\left(h_{1}-h_{10}\right)+\frac{\delta C}{\delta c_{2}}\left(c_{2}-C_{20}\right)+ \\
& \frac{\delta C}{\delta h_{2}}\left(h_{2}-h_{20}\right)+\frac{\delta C}{\delta V e}\left(V e-V e_{0}\right) \\
& \frac{1}{2} \frac{\delta^{2} C}{\delta c^{2}}\left(c_{1}-c_{0}\right)^{2}+\frac{1}{2} \frac{\delta^{2} C}{\delta h_{1}^{2}}\left(h_{1}-h_{0}\right)^{2}+ \\
& \frac{1}{2} \frac{\delta^{2} C}{\delta c_{2}^{2}}\left(c_{2}-C_{20}\right)^{2}+\frac{1}{2} \frac{\delta^{2} C}{\delta h_{2}^{2}}\left(h_{2}-h_{20}\right)^{2} \\
& \frac{1}{2} \frac{\delta^{2} C}{V_{e}^{2}}\left(V_{e}-V_{e 0}\right)^{2}
\end{aligned}
$$

This relation can be written down as:

$$
C \approx C_{0}+\sum_{i=1}^{5}\left[b_{i} X_{i}+b_{i i} X_{i}^{2}\right]
$$

$X_{1}=\frac{\left(c_{1}-c_{0}\right)}{\sigma_{1}} ; X_{2}=\frac{\left(h_{1}-h_{0}\right)}{\sigma_{2}} ; X_{3}=\frac{\left(c_{2}-c_{20}\right)}{\sigma_{3}}$

$$
X_{4}=\frac{\left(h_{2}-h_{20}\right)}{\sigma_{4}} ; X_{5}=\frac{\left(V_{e}-V_{e 0}\right)}{\sigma_{5}} ;
$$

and $b_{i}=c_{i} \sigma_{i} ; b_{i i}=c_{i i} \sigma_{i}^{2}$

where:

$$
b_{1}=\frac{\delta C}{\delta c_{1}} b_{2}=\frac{\delta C}{\delta h_{1}} \quad ; \quad b_{3}=\frac{\delta C}{\delta c_{2}} ;
$$

$b_{4}=\frac{\delta C}{\delta h_{2}} ; \quad b_{5}=\frac{\delta V_{e}}{\delta V_{e}} \quad b_{11}=\frac{\delta^{2} C}{\delta c_{1}^{2}} ;$

$b_{22}=\frac{\delta^{2} C}{\delta h_{1}{ }^{2}} ; \quad b_{33}=\frac{\delta^{2} C}{\delta c_{2}{ }^{2}} \quad b_{44}=\frac{\delta^{2} C}{\delta h_{2}{ }^{2}}$ and

$b_{55}=\frac{\delta^{2} C}{\delta V_{e}^{2}}$

where $\sigma_{i}$ is the standard deviation of the considered parameter.

If we assume that the variations of the parameters follow the normal distribution the first approximation can be writing [11,30]:

$$
\sigma_{C}^{2}=\sum_{i=1}^{5} b_{i}^{2}=\sum_{i=1}^{5}\left(\frac{\delta C}{\delta x_{i}}\right) \sigma_{i}^{2}
$$

The application of the relation (7) gives us:

$$
\begin{aligned}
& \sigma_{C}^{2}=\frac{S^{2} h_{1}^{2}}{V e^{2}} \sigma_{c 1}^{2}+\frac{S^{2} C_{1}^{2}}{V e^{2}} \sigma_{h 1}^{2} \\
& +\frac{S^{2} h_{2}^{2}}{V e^{2}} \sigma_{c 2}^{2}+\frac{S^{2} C_{2}^{2}}{V e^{2}} \sigma_{h 2}^{2}+\frac{S^{2}}{V e^{4}}\left(C_{1} h_{1}+C_{2} h_{2}\right) \sigma_{V e}^{2}
\end{aligned}
$$

And after simplification of this relation (8) we obtain:

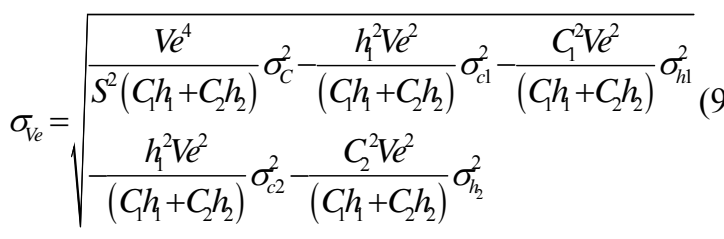




\subsection{Application: design of experiments}

In the previous chapters we defined reasons for a concentration values:

- Factor $\mathrm{C}_{1}$ : the concentration of ingredient Q1

- Factor $\mathrm{C}_{2}$ : the concentration of ingredient Q2

- Factor $\mathrm{V}_{\mathrm{e}}$ : the quantity of water

For a traditional experimental design, we research the response system facing varying input values. In this case we adjust these factors to give the corresponding response of system.

In our case we consider uncertain parameters values:

- the concentration values $\mathrm{C} 1$ and $\mathrm{C} 2$ depend on several parameters as certain treatments and there are uncertain and uncontrollable.

- Levels h1 and $\mathrm{h} 2$ are adjustable while acting on the quantity or weights of products Q1 and Q2.

- the volume of water Ve depends on the values of $\mathrm{C} 1$ and $\mathrm{C} 2$.

To resolve this problem we will use in this paper the statistical real data of the production. Afterwards we are going to calculate tolerances for these parameters. For a more details see the results of this study.

Statistical data of the process gives us the standard deviation of concentrations $\mathrm{C}, \mathrm{C} 1, \mathrm{C} 2$ : and quantity of water $\mathrm{Ve}$. These are respectively:

$$
\sigma_{c}=0.2, \sigma_{c 1}=0.6, \sigma_{c 2}=0.6 ; \sigma_{V e}=0.5
$$

Let consider that the value targets for a good concentration are following:

$\mathrm{m}_{1}=200 \mathrm{~kg}$ with a concentration $\mathrm{C}_{10}=0.25$

$\mathrm{m}_{2}=80 \mathrm{~kg}$ with a concentration $\mathrm{C}_{20}=0.07$

Target volume of water: $\mathrm{Ve}_{0}=650 \mathrm{~L}$

Capacity of a mixing tank $=1 \mathrm{~m}^{3}$

Section of mixing tank $S=1 \mathrm{~m}^{2}$

Under these conditions the standard deviation of the concentration can be determined while applying the following equation: $\sigma_{C}=0.427$

The tolerance in the volume of water is:

$\mathrm{IT}_{\mathrm{Ve}}=0.26$

The tolerances of the parameters are given by the following table.
Table I: Limit values of parameters

\begin{tabular}{|c|c|c|}
\hline Parameter & Unit & Value \\
\hline $\mathrm{c}_{1 \min }$ & $\mathrm{g} / \mathrm{mm}^{3}$ & 0.22 \\
\hline $\mathrm{c}_{1 \max }$ & $\mathrm{g} / \mathrm{mm}^{3}$ & 2.27 \\
\hline $\mathrm{c}_{2 \min }$ & $\mathrm{g} / \mathrm{mm}^{3}$ & 0.06 \\
\hline $\mathrm{c}_{2 \max }$ & $\mathrm{g} / \mathrm{mm}^{3}$ & 0.08 \\
\hline $\mathrm{h}_{\min }$ & $\mathrm{M}$ & 0.2 \\
\hline $\mathrm{h}_{\max }$ & $\mathrm{m}$ & 0.2 \\
\hline $\mathrm{V}_{\text {emin }}$ & 1 & 800 \\
\hline $\mathrm{V}_{\text {emax }}$ & 1 & 950 \\
\hline $\mathrm{C}_{\min }$ & $\mathrm{g} / \mathrm{mm}^{3}$ & 0.5 \\
\hline $\mathrm{C}_{\max }$ & $\mathrm{g} / \mathrm{mm}^{3}$ & 0.7 \\
\hline Target value of $\mathrm{C} 1$ & $\mathrm{~g} / \mathrm{mm}^{3}$ & 0.25 \\
\hline Target value of $\mathrm{C} 2$ & $\mathrm{~g} / \mathrm{mm}^{3}$ & 0.07 \\
\hline Target value of C & $\mathrm{g} / \mathrm{mm}^{3}$ & 0.6 \\
\hline
\end{tabular}

The figure 5 represents the network ICPN model of mixing system (figure 4). In this model place $\mathrm{P}_{01}$ and $\mathrm{P}_{02}$ represent stocks to the entries of system. Places $\mathrm{P}_{\mathrm{c} 1}, \mathrm{P}_{\mathrm{h} 1}, \mathrm{P}_{\mathrm{c} 2}$ and $\mathrm{P}_{\mathrm{h} 2}$ are respectively the quantity of product $\mathrm{C}_{1}$ in tank 1 , the level in tank 1 , the quantity of product $\mathrm{C}_{2}$ in tank 2, the level in tank 2. The places $P_{e}$ and $\mathrm{P}_{\mathrm{c}}$ represent respectively the quantity of water and the concentration of finished mixing operation. Place Pc is a place of control which prevents the simultaneous crossing of the transitions $\mathrm{T}_{1}$ and $\mathrm{T}_{4}$.

Finally, after the ICPN process model is building, we can analyze its structural properties and we prove that most P-time PN structural properties can be extended to IFCPN [15].

When using information on production data, the method was applied in order to calculate the limits of the intervals (Figure 5).

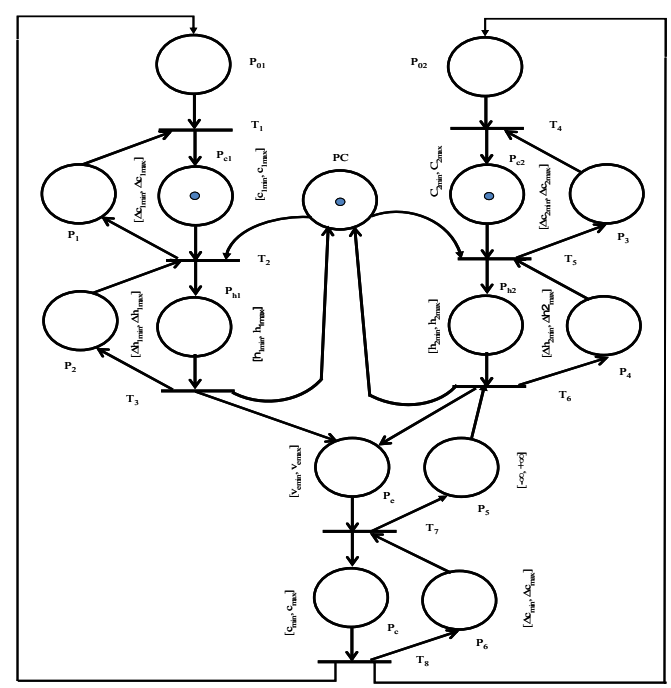

Figure 5. Validity intervals of the ICPN model 


\section{Computing a robust command}

The process model is defined by valid fuzzy intervals. Under some particular assumptions, we can usually extend the structural properties of ICPN to analyse the structural properties Interval Fuzzy PN model. Our goal is to provide the internal and external robustness system [6].

The robustness of a dynamic system is defined as its capacity to maintain the properties specified in the face any deviations. The robustness characterizes the ability of system with input fluctuations. For each system two types of disturbances are defined [11, 12, 33] external and internal: the internal disturbance is due to the change of the states of the organs of the machine. The external derivate is due to input fluctuation.

So we define two types of robustness $[11,26]$ :

A passive and an active robustness. The first one is insured when reaching the objectives without adjustment. On the other hand the second type is insured when it can not reach objectives without adjustment and we need to calculate a new command.

The figure 6 illustrates the notion of robustness and their margins. The determination of which is crucial for the calculation of a new command in the event of violation of the constraints.

Exceeding these values involves a violation of the constraints.

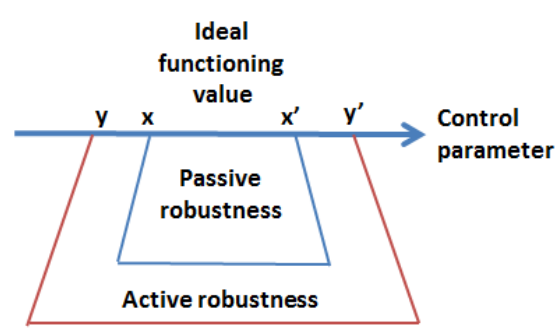

Figure 6. Margins of robustness

This study concerns the problem of the passive robustness of the mixing system in the case of derivatives of the values of the input products $\mathrm{C} 1$ and $\mathrm{C} 2$. In this case the calculated control system must be able to compensate for these deviations and specifications on the concentration $\mathrm{C}$ of the final product must not be violated.

Indeed, the mixing systems are subject to disruptions. Their causes vary: changes in operating times, variations in the quality of raw materials, state of the process...

In this work we propose to build a robust control synthesis tool. The tool uses static intervals constraint on the components. Thus, this control is ensured through a few real-time adjustment operations. The calculation of these settings is made as a function of the static intervals assigned to the parameters and using the developed graph (Figure 7) relating to the Fuzzy Petri Net model.

In this developed graph the nodes correspond to the transitions of the Petri net of the figure 5.

For each place $\mathrm{p}$ of PN model we associate two arcs. The value of first arc from place to transition is obtained by:

$$
\mathrm{X}_{\mathrm{p}}=\mathrm{a}-\mathrm{C} . \mathrm{m}
$$

The value of second one from transition to place is calculated by:

$$
Y_{p}=-b+C \cdot m
$$

Where $\mathrm{C}$ represents a periodic control of the parameters that is obtained with implementation of an algorithm [26].

In our case we for the IFPN of the Figure 5 we suppose that $\mathrm{C}=1$ then we obtain the developed graph (figure 7).

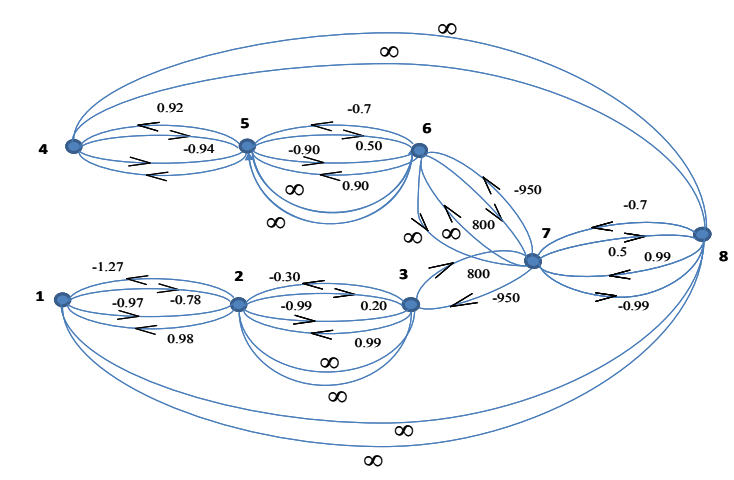

Figure 7. Developed Graph

\section{Simulation and results}

The monitoring of the system during a period of one month allowed us to operate the variations of the output measures: concentration $\mathrm{C} 1$, concentration $\mathrm{C} 2$ and the final product $\mathrm{C}$.

The Fuzzy PN model has been simulated with the values of Table 1. Our aim was to preserve the specifications on these parameters. The results obtained (figure 8) show the robustness 
of our model. Indeed the variation of the measured concentration values do not exceed must respect the constraint specification. In these conditions the process is robust.

The following production sequence takes place: first phase is preparation of the mixing product.

Firstly, the valve V1 is open, an ingredient Q1 flows into tank. When the level h1 in the tank is

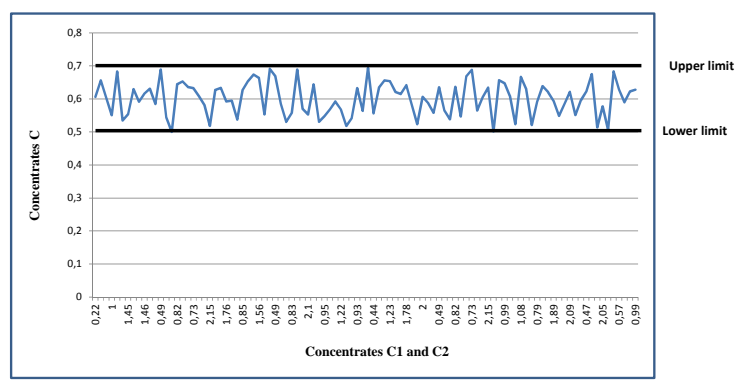

Figure 8. Variation of concentration value

reached $\left(h_{1 \min } \leq h_{10} \leq h_{1 \max }\right.$ ), the valve $\mathrm{V} 1$ is closed and the valve V2 is opens, ingredient Q2 flows into the tank. When the $\mathrm{h} 2$ in the tank is reached $\left(h_{2 \min } \leq h_{20} \leq h_{2 \max }\right)$ and valve V2 closes.

After the activation of sensors $\mathrm{h} 1$ and $\mathrm{h} 2$, valve $\mathrm{V} 3$ is open, water Qe flows into the mixing tank. When the level h3 in the tank is reached ( $\left.h_{3 \min } \leq h_{30} \leq h_{3 \max }\right)$, valve V3 is closed and the agitator will run for $3 \mathrm{mn}$ until the batching cycle is complete.

\section{Control sequence:}

(1) S0: initialization phase (the mixing tank is empty).

(2) S1: V1 is open, the Fill with Q1.

(3) S2: When the level h1 is reached then V1 is closed and V2 is opened.

(4) S3: If Level h2 is reached then V2 is closed.

During every phase of the preparation of the product, the ingredient level of must be controlled. If the total level rises to greater than $\mathbf{9 5 \%}$ of tank's mixing capacity, the command will generate an alarm and the process must be stopped.

\section{Considered faults:}

We considered three faults $\mathrm{f}=\{\mathrm{f} 1, \mathrm{f} 2, \mathrm{f} 3\}$, where:

- f1: valve V1 stuck close. This means that the tank is empty. Controller waits for event h1 which cannot occur because of the fault.
- f2: valve V2 stuck close. Controller waits for event h2 which cannot occur because of the fault.

- f3: valve V3 being stuck open. This fault causes an overflow.

- f3: The third considered fault is sensor h3 which stays in close position. It means there is an overrun of $95 \%$ of the tank capacity but the sensor is faulty.

Figure 9 shows the three membership functions associated to h1, h2 and V3.

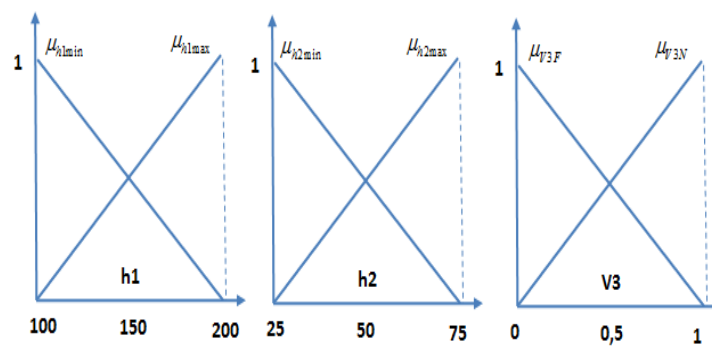

Figure 9. Membership functions

$$
\begin{aligned}
& \left\{\begin{array}{l}
\mu_{h 1 \text { min }}=\frac{-1}{100} h 1+2 \\
\mu_{h 1 \text { max }}=\frac{1}{100} h 1-1
\end{array}\right. \\
& \left\{\begin{array}{l}
\mu_{h 2 \min }=\frac{-1}{50} h 2+\frac{3}{2} \\
\mu_{h 2 \max }=\frac{1}{50} h 2-\frac{1}{2}
\end{array} ; \quad\left\{\begin{array}{l}
\mu_{V 3 F}=-V 3+1 \\
\mu_{V 3 N}=V 3
\end{array}\right.\right.
\end{aligned}
$$

Fuzzy Rules:

$\mathrm{R} 1$ : if $\mathrm{V} 1$ is max and $\mathrm{V} 2$ is min then $\mathrm{V} 3$ is ok $\mathrm{R} 2$ : if $\mathrm{V} 1$ is max and $\mathrm{V} 2$ is maw then $\mathrm{V} 3$ is fault. In these conditions we can write:

$$
\mu(V 3)=\max \left\{\begin{array}{l}
\min \left(\mu_{\max V 1}, \mu_{\min V 2}, \mu_{V 3 F}\right), \\
\min \left(\mu_{\max V 1}, \mu_{\max V 2}, \mu_{V 3 N}\right)
\end{array}\right\}
$$

Suppose that at a given instant the quantities measured are the following V1 $=170$ and V2 = 40. Under these conditions we shall have (Figure 10) $\mu_{V 1 \max }=0.8, \mu_{V 2 \min }=0.4, \mu_{V 2 \max }=0.8$, from where:

$\mu(V 3)=\max \left\{\min \left(0.8, \mu_{V 3 F}\right), \min \left(0.4, \mu_{V 3 N}\right)\right\}$

The defuzzification by the method of the first maximum gives $\mathrm{V} 3=0$, we conclude that the valve V2 is in default. 


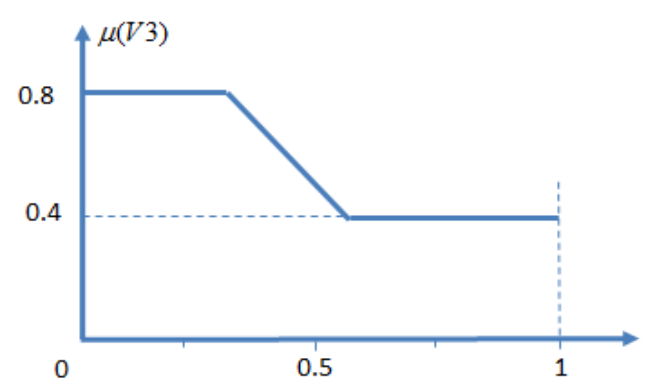

Figure 10. Membership function of the fuzzy sub-set

\section{Conclusion}

In this paper we present an approach dealing with automatic control specification of an industrial process. We propose a control loop which is able to maintain a constant concentration value of product despite the fact that the concentration values of $\mathrm{C} 1$ and $\mathrm{C} 2$ are not deterministic.

The applied methodology is based upon the use of an IFCPN model. The design experiments were used in order to compute the validity intervals of the critical parameters. The manual control generated a great variety of different settings but they were not all taken into account.

The IFCPN model with its completely defined intervals has been built. Our approach is validated through an industrial application and for this validation we have chosen the simplest case. However, the proposed approach can be extended to the diagnosis analysis of the multiple causes and common cause failures.

\section{Acknowledgments}

The authors would like to thank the comments provided by the anonymous reviewers and editor, which helped the authors improve this paper significantly.

\section{References}

1. Basile P. Chiacchio, \& G. D. Tommasi. An efficient approach for online diagnosis of discrete event systems. IEEE Trans. on Automatic Control, vol. 54, no. 4, pp. 748759, 2009.

2. Belhadef Rachid, Ahmed Hafaifa, Nadji Hadroug \& Mohamed B., Reliability Evaluation Based on a Fuzzy Expert System: Centrifugal Pump Application, Studies in Informatics and Control, ISSN 1220-1766, vol. 25(2), pp. 181-188, 2016.
3. Bugarin J. \& S, Barro. Fuzzy Reasoning Supported by Petri Nets. IEEE Tran. Fuzzy Syst., vol. 2, no. 2 pp. 135-150, 1994.

4. Cardoso J. \& H. Camargo (Eds.). Fuzziness in Petri Nets. Studies in Fuzziness and soft Computing, vol. 22, New Work: PhysicaVerlag, 1999.

5. Cassandras C. G. \& S. Lafortune. Introduction to Discrete Event Systems. Kluwer Academic, 2008.

6. Chen J. \& Patton, R. J., Robust Model-Based Fault Diagnosis for Dynamic Systems. Kluwer Academic Publishers, 1999.

7. Chen S. M., Fuzzy Backward Reasoning Using Fuzzy Petrin Nets. IEEE Tran.Syst., Man, Cybern., vol. 30, no. 6, pp. 846-856, Dec. 2000.

8. Chow T.S., Testing Design Modelled by Finite-State Machines. IEEE Trans. S.E. 4, 3, 1978.

9. David R. \& H. Alla. Petri Nets for Modeling of Dynamic Systems. A servy, Automatica, vol, 30, no, 2, pp. 175-202, 1994.

10. Dhouibi H., B. Lobna, Mhamdi L. \& Simeu Abazi Z., Using interval constrained Petri nets and automata for diagnosis of dynamic systems. International Review on Computers and Software (IRECOS), ISSN: 1828-6011, Vol. 9, No 5 (2014), pp 735-743.

11. Dhouibi H., Collart Dutilleul S., Nabli L. \& Craye E., Computing intervals of Intervals Constrained Petri Nets 17 th IMACS World Congress, Paris, pp. 440-446., Juillet 2005.

12. Dhouibi H., Collart Dutilleul S., Nabli L . \& Craye E., Using Interval Constrained Petri Nets for Reactive Control Design: A tobacco manufacturing application. The International Journal Manufacturing Systems and Production (IJMSP), Volume 9, NOs. 3-4, pp 217-228, ISSN (printed): 0793-6648, 2008.

13. Dhouibi H., K. Ouni, L. Nabli \& E. Craye. A modelling approach of robustness control for regulation system with Temporal end non Temporal Constraints trough Petri Nets, International Conference on Communications, Computing and control Applications (CCCA), Mars 3-5, Hammamet - Tunisia 2011. 
14. Dhouibi H. Utilisation des réseaux de Petri à intervalle pour la régulation d'une qualité. Thèse de Doctorat de l'Ecole Centrale de Lille France, 2005.

15. Dubois E. Kerre, R. Mesiar \& H. Prade. Fuzzy interval analysis. Fundamentals of Fuzzy Sets, pages 483-581. Kluwer, 2000.

16. Frank P., Advances in observer-based fault diagnosis. Proc. TOOLDIAG'93, CERT, Toulouse, France, pp. 817-836, 1993.

17. Fujiwara S. \& al., Test selection based on finite state models. IEEE Trans. on S.E., Vol. 17, No. 6, June 1991, pp. 591-603.

18. Goenenc G., A method for the design of fault detection experiments. IEEE Trans. Computer, Vol. C-19, pp. 551-558, June 1970.

19. Hafaifa A., F. Laaouad \& K. Laroussi. Fuzzy Approach Applied in Fault Detection and Isolation to the Compression System Control. Studies in Informatics and Control, vol 19(1), 2010.

20. Hans-Peter Lipp \& Rolf Gunther. A Fuzzy Petri Net Concept for Complex Decision Making Processes in Production control. In Proc. First EUFIT'93, European Congress on Fuzzy and Intelligent Technologies, September 7-10, Aachen, Germany, 1993.

21. Heloisa Scarpelli \& Fernando Gomide. Fuzzy Reasoning and High Level Fuzzy Petri Nets. In Proc EUFIT'93, European Congress on Fuzzy and Intelligent Technologies, Aachen, Germany, September 7-10,1993, pp. 600-605.

22. Henri Klajnmic. Intervalles de confiances et intervalles de tolérance. EDF recherche et développement. 34 ${ }^{\text {ème }}$ Journées de Statistique, Bruxelles, Mai 2002.

23. Isermann R., Fault diagnosis of machines via parameter estimation and knowledge processing. Tutorial paper, Automatica 29(4), 815-835, 1993.

24. Isermann R., Model-based Fault-detection and Diagnosis Status and Applications. Annual Reviews in Control, vol. 29, 2005, 71-85.

25. Jensen K. \& G. Rozenberg (Eds.). HighLevel Petri Nets: Theory and Application. SpringerVerlag, 1991.
Khansa W., Les réseaux de Petri Ptemporels: Contribution à l'étude des Systèmes à Evénements Discrets. Thèse de Doctorat de l'Université de Savoie, France, Mars 1997.

26. Looney G., Fuzzy Petri Nets for Rule-Based Decision making. IEEE Tran. Syst. Man., Cybern, vol. 18, no, 1, pp. 178-183, Jan./Feb. 1988.

27. Maurice Pillet. Appliquer la Maîtrise Statistique de Procédé. Edition d'Organisation 1995-2000. J. pp. 395-398.

28. Miguel Hernandez, Basilio Del Muro, Domingo Cortes \& Juan Carlos Sanchez. An Easy to Apply Methodology for Fault Detection and Isolation in Linear Systems. Studies in Informatics and Control, ISSN 1220-1766, vol. 21 (3), 275-282, 2012.

29. Moore R. E., Interval Analysis. Prentice Hall, New Jersey, 1966.

30. Murata T., Petri nets: Properties, Analysis and Applications. Proceedings IEEE, vol. 77(4), 1989, pp. 541-580.

31. Oliveira P. W., Fundamentos de Matemática Intervalar $1 a$ ed. Instituto de Informática da UFRGS: SAGRA-Luzzato, 1997.

32. Patton R., Robust model-based fault diagnosis: the state of the art. IFAC Fault Detection, Supervision and Safety for Technical Processes, Espoo, Finland, pp. 1-24, 1994.

33. Peterson J. L., Petri net theory and modeling of systems. Prentice-Hall, Inc, 1981.

34. Reisig W., Petri nets: an introduction. Berlin: Springer-Verlag, 1985.

35. Witold Pedrycz \& Fernando Gomide. A Generalized Fuzzy Petri Net Model. In IEEE Transactions on Fuzzy Systems, IEEE Transactions on Fuzzy Systems, 295-301.

36. Zadeh L. A.. Fuzzy Sets. Information and Control, Vol. 8, 1965, pp. 338-353.

37. Zhuo M. C., \& F. Dicsare. Petri Net synthesis for Discrete Event Control of Manufacturing Systems. Boston, MA. Kluwer, 1993. 